\title{
Role of venography in assessing patients with superior caval obstruction caused by bronchial carcinoma for bypass operations
}

\author{
J F DYET AND K MOGHISSI \\ From the Department of Radiology, Hull Royal Infirmary, Hull, and Humberside Cardiothoracic Centre \\ Castle Hill Hospital, Cottingham
}

ABSTRACT The value of venography in assessing the level of obstruction in mediastinal block an $\$$ hence the selection of patients for bypass grafting is demonstrated, and an illustrative case is̊ presented.

Superior vena caval obstruction is a particularly distressing complication of bronchial carcinoma, occurring in $4.6 \%$ of cases, ${ }^{1}$ for which the usual method of treatment is radiotherapy. However, innominate vein to right atrial appendage bypass grafts have been used to relieve the obstruction in certain patients with severe symptoms. ${ }^{2}$

Before considering surgical treatment, it is necessary to map out the superior mediastinal venous system, ${ }^{3}$ and the purpose of this paper is to show how preoperative superior vena cavography is of value in determining the level of obstruction and whether or not there is retrograde propagation of thrombus.

\section{Methods}

Superior vena cavography is performed using a rapid sequence film-changer. The patient lies in the supine position breathing quietly throughout the examination, to eliminate any tendency to a Valsalva manoeuvre. ${ }^{3}$ The equipment required is two $30 \mathrm{ml}$ syringes, each containing $25 \mathrm{ml}$ of Urografin 290 , and two 16-gauge needles with connecting tubes.

Injections are made by hand simultaneously into the basilic veins in both antecubital fossae, and films of the innominate veins and superior vena cava are taken at a rate of one per second for eight seconds. When caval obstruction is severe, it is necessary to raise both arms to obtain a good bolus of contrast into the innominate veins and superior vena cava.

All the 39 patients in this series were thought

Address for reprint requests: Dr JF Dyet, Hull Royal Infirmary, Anlaby Roar, Hull.

to have either superior vena caval obstructio caused by tumour, or mediastinal involvement by tumour, which might be involving the superior vena cava but as yet not causing obstruction.

\section{Results}

The table shows the findings at cavography i⿺辶⿸ 39 patients. Figures 1 and 2 illustrate the two main levels at which obstruction may occur.

The seven patients with obstruction by tumou色 involving the superior vena cava at or below the azygcs vein, in all of whom symptoms were severe, were selected for bypass grafting. Af these patients had rapid relief of their symp toms.

Postoperative cavography demonstrated paten grafts in six of the seven patients. In one case the graft could not be demonstrated for techo nical reasons, although the patient's symptoms were relieved.

\section{Illustrative case}

A 49-year-old steel fitter (RT) was first seeft on 8 September 1976. He complained of swelling of the neck for three to four weeks, and pain in the head on stooping. He had signs of caval

Table 1 Results of superior vena cavography

\begin{tabular}{|c|c|}
\hline Site of obstruction & Number of cases \\
\hline $\begin{array}{l}\text { Above the azygos vein } \\
\text { The azygos vein or SVC below it } \\
\text { Tumour involving the SVC but } \\
\text { not obstructing it } \\
\text { SVC displaced but not obstructed } \\
\text { Total }\end{array}$ & $\begin{array}{r}16 \\
7 \\
1 \\
15 \\
39\end{array}$ \\
\hline
\end{tabular}




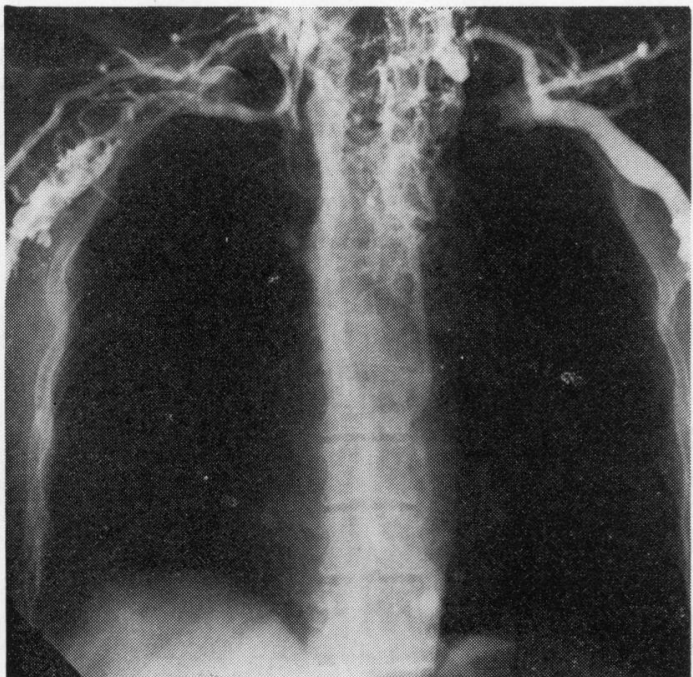

Fig 1 Obstruction of the superior vena cava and both innominate veins. Venous flow via the accessory hemiazygos system to the azygos and inferior vena cava.

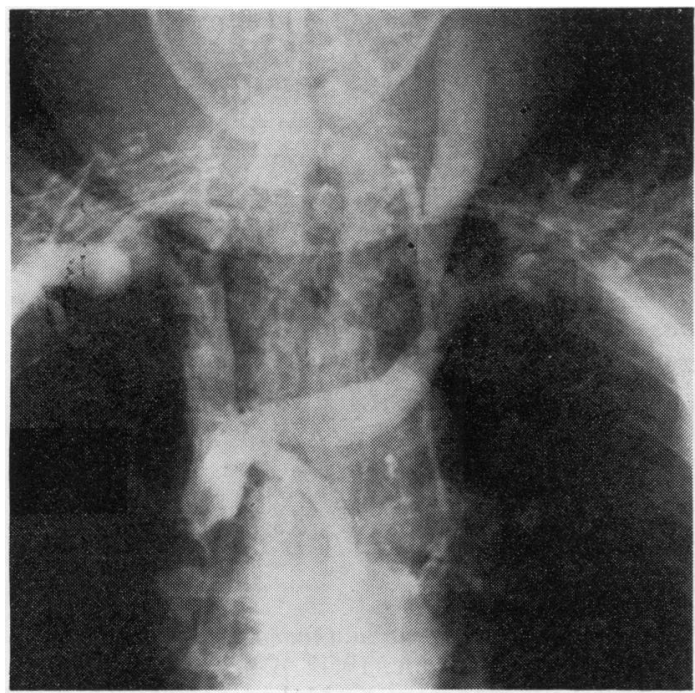

Fig 2 Obstruction below the azygos vein.

obstruction (fig 3). A chest radiograph showed widening of the right side of the mediastinum and enlargement of the right hilum. Bronchoscopy and biopsy revealed an undifferentiated carcinoma. A superior vena cavogram (fig 4) showed narrowing of the superior vena cava, with involvement of the azygos vein.

At operation the mean pressure in the innominate vein was $35 \mathrm{mmHg}$ and in the right atrium $2 \mathrm{mmHg}$. A $10 \mathrm{~mm}$ Dacron graft was

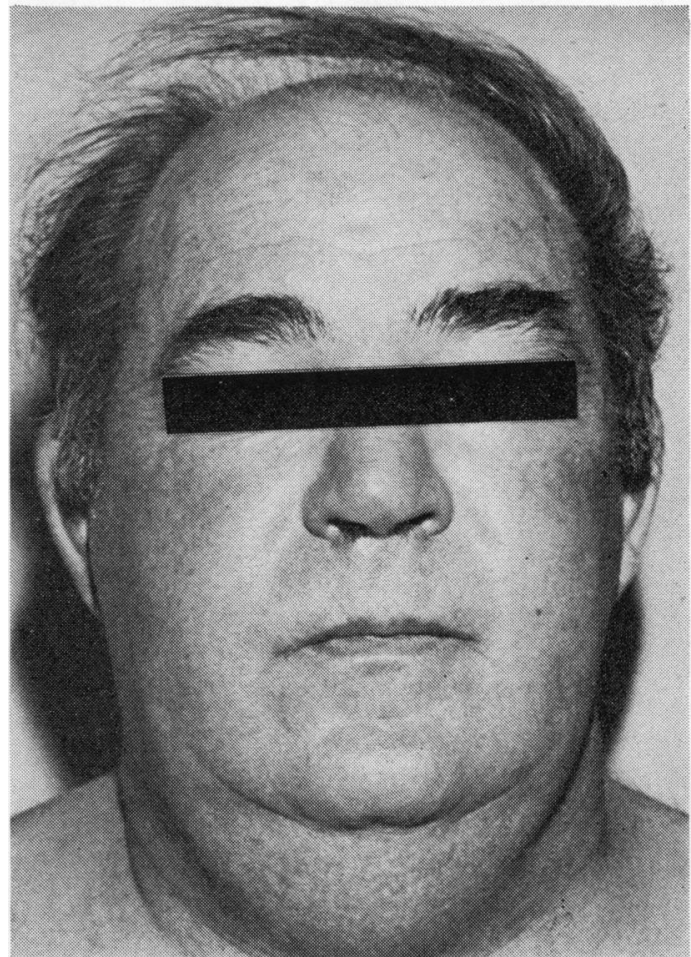

Fig 3 Patient $R T$ before operation.

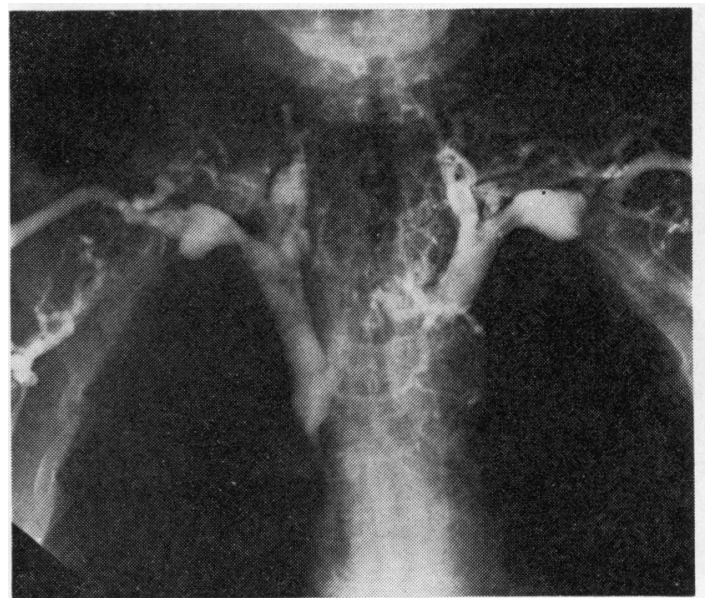

Fig 4 Venogram showing obstruction of the superior vena cava including the azygos vein.

inserted between the left innominate vein and the right atrial appendage. Mean pressures at the end of operation were $10 \mathrm{mmHg}$ in the innominate vein and $2 \mathrm{mmHg}$ in the right atrium. The swelling of the face and neck 


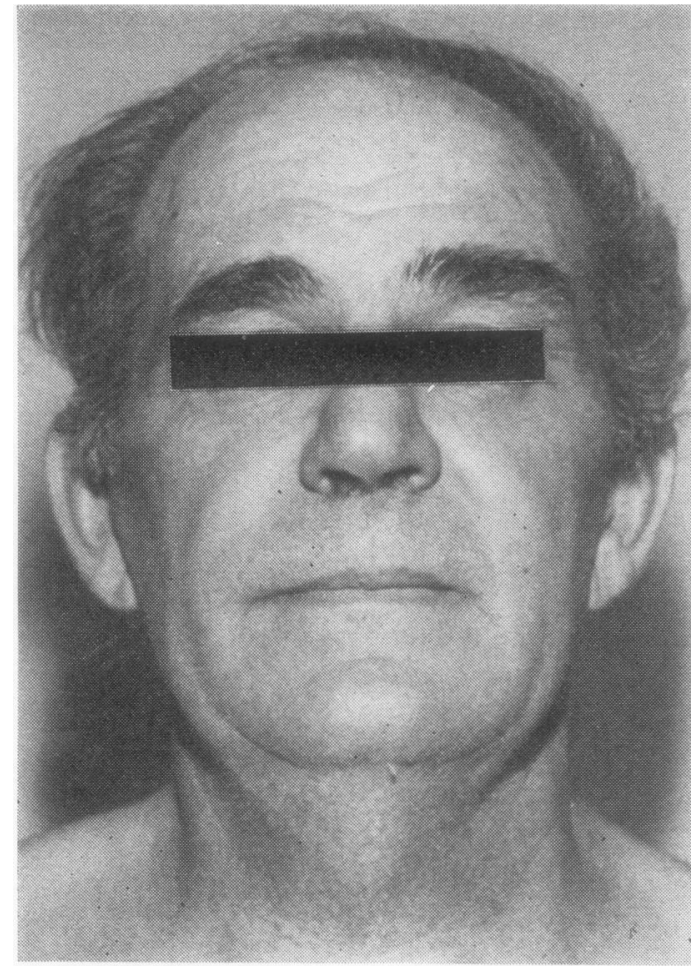

Fig 5 Patient $R T$ three days after operation.

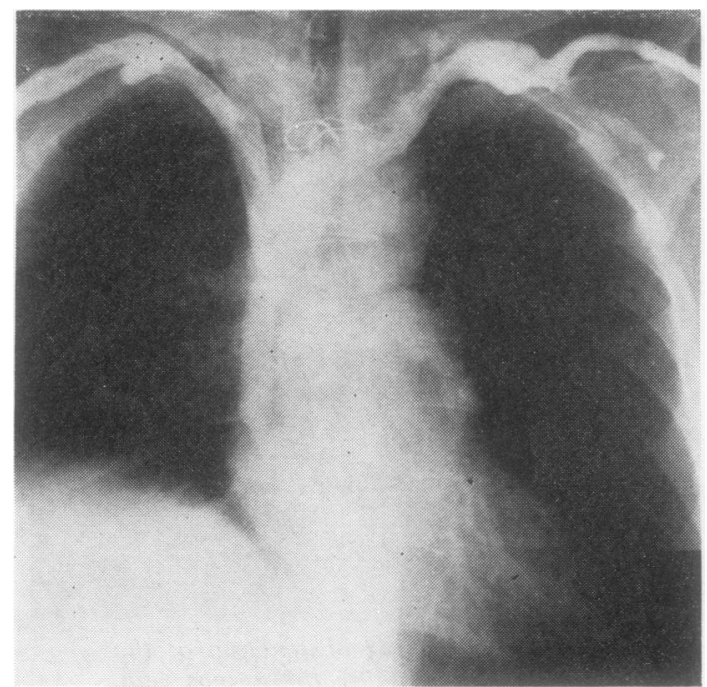

Fig 6 Postoperative venogram showing the graft from the left innominate vein to the right atrial appendage.

rapidly subsided (fig 5). Postoperative venography showed a patent graft (fig 6). The patient had a course of radiotherapy and was then discharged. He remained well and caval obstruc $\stackrel{\overrightarrow{\vec{P}}}{\vec{P}}$ tion did not recur. He was eventually readmitte 11 months later with cerebral metastases, an died on 9 September 1978. At necropsy the in nominate to right atrial appendage graft was still patent.

\section{Discussion}

When superior vena caval obstruction occurs, a abundant collateral circulation may open up. $\frac{\vec{P}}{x}$ The efficiency of this collateral circulatioif determines the degree of disability. If theo obstruction is above the azygos vein collaterad pathways are numerous and the patient tolerateso the condition ketter (fig 1). ${ }^{5}$ However, wherf the obstruction occludes the azygos vein or is below it, there are relatively few collaterat pathways, the venous pressure is much highes and the disability is correspondingly greater It is these patients with severe symptoms wheo are suitable for grafting, as the graft can beg performed only when the innominate veins are patent.

Roswit et $a l^{5}$ report a $76 \%$ remission rate in 38 patients treated by radiotherapy, although they do not indicate the differential figures foo obstruction above or below the azygos vein? None of the patients in our series had and further episodes of caval obstruction, althougl in Roswit's series the average duration of remis sion was only 14 weeks.

Patients with superior vena caval obstruction caused by tumour involvement at or below the azygos vein may have their symptoms rapidly relieved by bypass grafting. This is a palliative procedure which may be combined with radio therapy and which improves the quality of the patient's remaining life.

\section{References}

1 Le Roux BT. Bronchial carcinoma. EdinburghN E and S Livingstone, 1968: 104-7.

2 Avasti BR, Moghissi K. Malignant obstruction of the superior vena cava and its palliation. N Thorac Cardiovasc Surg 1977; 74:244-7.

3 Rinker CT, Templeton AW, Mackenzie J? Ridings E, Almond CH, Kiphart R. Combinee superior vena cavography and azygography in patients with suspected lung carcinoma: Ratiology 1967; 88:441-5.

4 Okay NH, Bryk D. Collateral pathways in occlu. sion of the superior vena cava and its tributaries尺 Radiology 1969; 92:1493-8.

5 Roswit B, Kaplan G, Jacobson HG. The superio vena cava obstruction syndrome in bronchogenic carcinoma. Radiology 1953; 61:722-36. 